\title{
OPTIMIZATION POSSIBILITIES OF PROPERTIES OF NITI ALLOYS USED AS TRAUMATOLOGY IMPLANTS
}

\author{
Michal KOPELENT, Monika LOSERTOVÁ, Michal ŠTENCEK, Kateřina KONEČNÁ, \\ Bedřich SMETANA, Jaromír DRÁPALA \\ VSB - Technical University of Ostrava, Faculty of Materials Science and Technology, Ostrava, \\ Czech Republic, EU, michal.kopelent@vsb.cz
}

https://doi.org/10.37904/metal.2021.4271

\begin{abstract}
Shape memory alloy represents metallic material that can return to its original forms, shapes, or sizes when subjected to a process of memorization between two transformation phases. The basic application of these materials is always simple, i.e. where the material can be easily deformed by an external force and will recover its original forms when heated at a certain temperature. NiTi alloy is mainly characterized by its special properties, namely the shape memory effect and superelastic behavior, as well as the excellent corrosion resistance, high strength, low modulus of elasticity and biocompatibility. Due to its superelasticity, NiTi resembles to some human rigid tissues, including bones and tendons that enables its using in implants or tools for many medical cases in orthopedics, neurology, cardiology, interventional radiology, endodontics, etc. In this work, the effect of thermal treatment on physical-metallurgical properties of NiTi alloy was studied. Flat samples of $\mathrm{NiTi}$ alloy with a composition of 50.6 at\% $\mathrm{Ni}$ and 49.4 at\% Ti were solution treated at $850{ }^{\circ} \mathrm{C}$ and subsequently aged at $450^{\circ} \mathrm{C}$. The microstructures in as-received, solution treated or solution treated and aged stages were examined by means of optical or scanning electron microscopies. The analysis of the heat treatment effect on the microstructure and transformation temperatures was completed by Vickers microhardness measurement and by differential scanning calorimetry.
\end{abstract}

Keywords: NiTi, solution treatment, aging, superelasticity, transformation temperature

\section{INTRODUCTION}

Shape memory alloys (SMAs) are a group of metallic alloys that can return to their original form (shape or size), depending on the temperature or magnetic field. These changes are associated with the transformation between a martensite and austenite phase, with the possible formation of a transient R-phase. The phase transformation can be induced thermally (by heating/cooling) in a certain temperature range or mechanically (by loading/unloading) in some temperature modes [1]. In nearly equiatomic NiTi alloys, phase transformation temperatures can change by up to $10^{\circ} \mathrm{C}$ with a change in Ni content of $0.1 \mathrm{at} \%$ [2].

SMAs can exist in two different phases (martensite and austenite). The austenitic structure is stable at higher temperatures and the martensitic structure is stable at lower temperatures. When SMAs are heated, the martensite begins to transform into the austenitic phase. The austenite start temperature $A_{s}$ (Austenite start) is the temperature at which this transformation begins, and the final austenite temperature $A_{f}$ (Austenite finish) is the temperature at which this transformation is completed. The austenite $\leftrightarrow$ martensite transformation is also possible under a mechanical loading [3]. During cooling, the structure transforms back to martensite at the initial martensite start temperature $M_{s}$ (Martensite start) and the conversion is completed when martensite finish temperature $M_{f}$ (Martensite finish) is reached [4]. The highest temperature at which martensite can no longer be induced by the applied stress is called $M_{d}$ and above this temperature the SMA is permanently deformed as a common metallic material [5]. 
Superelasticity refers to reversible inelastic deformation, in which a large part of the deformation recovers after unloading. For NiTi alloys, this phenomenon relies on the stress-induced formation of martensite from the parent austenite during loading and on the reverse martensite $\rightarrow$ austenite transformation during unloading in relation with the mobile interfaces between the austenitic and martensitic phases.

Comparing human bone the high rigidity of metallic materials used in biomedicine often leads to stress shielding effect in the bone, which prolongs or interrupts healing time and can even lead to implant failure. Due to its superelasticity, NiTi alloy resembles to some human rigid tissues, including bones or tendons that enables its using in different medical fields. Indeed, the NiTi alloys used in producing medical implants, tools or devices, such as intravascular stents for cardiovascular surgery, plates or nails for healing fractures in traumatology, orthodontic wires or root tools for cleaning dental canals in dentistry, laparoscopy tweezers or implants for many medical cases in orthopedics, surgery, neurology, interventional radiology, etc. [6,7].

To evaluate possibilities of functional properties optimization in following experimental research the study of heat treatment effect on the transformation temperatures, microstructure features and microhardness was carried out for NiTi samples in as-received, solution treated or solution treated and aged conditions.

\section{EXPERIMENTAL}

For the experiment, NiTi sheet of the required composition according to ASTM F 2063 (in the range of 54.5 to 57.0 wt\% Ni for formed products), purchased from Baoji Hanz Material Technology Co., Ltd., (China) was used. A thickness of the sheet was $3.5 \mathrm{~mm}$, and the transformation temperature $A_{f}$ was certified by supplier for $15^{\circ} \mathrm{C}$. A set of 17 flat samples were prepared for further experiments (Table 1). The composition of the alloy was certified by the sheet supplier in the ranges: Ni 55.4-56.2 wt\%, C $\leq 0.07 \mathrm{wt} \%, \mathrm{H} \leq 0.005 \mathrm{wt} \%, \mathrm{O} \leq 0.050$ $w t \%, N \leq 0.05 w t \%$.

Table 1 List of samples

\begin{tabular}{|c|c|c|}
\hline \multicolumn{1}{|c|}{ Experimental work } & Stage of treatment & Number of samples \\
\hline \multirow{3}{*}{ Microstructure and microhardness analysis } & $\mathrm{AR}$ & $\begin{array}{c}2 \times \text { upper surface } \\
2 \times \text { transversal section }\end{array}$ \\
\cline { 2 - 3 } & $\mathrm{ST}$ & 2 \\
\cline { 2 - 3 } & $\mathrm{ST}+\mathrm{A}$ & 2 \\
\hline \multirow{3}{*}{ DSC } & $\mathrm{AR}$ & 3 \\
\cline { 2 - 3 } & $\mathrm{ST}$ & 3 \\
\cline { 2 - 3 } & $\mathrm{ST}+\mathrm{A}$ & 3 \\
\hline
\end{tabular}

Note: $A R$-as-received; $S T$ - solution treated; $S T+A$ - solution treated + aged

Two samples were submitted to the solid solution treatment at $850{ }^{\circ} \mathrm{C}$ under flowing argon in a Linn HT1800 high temperature apparatus. Water quenching was applied to ensure retaining the structure existing at the annealing temperature. After quenching, one sample was aged at $450{ }^{\circ} \mathrm{C}$ and then quenched again in the water. The procedure of the heat treatment is shown on the schematic in Figure 1.

Before examining the microstructure, the samples were grinded and polished using a LaboPol-5 grinding machine. Abrasive papers of grain sizes up to P2500 were used before polishing on a linen cloth and a suspension of $\mathrm{Al}_{2} \mathrm{O}_{3}$ with a particle size of $1 ; 0.3$ and $0.05 \mu \mathrm{m}$. Afterwards, the samples were etched in the solution composed of $3 \mathrm{ml} \mathrm{HF}(38-40 \%), 5 \mathrm{ml} \mathrm{HNO} 3(65 \%)$ and $3 \mathrm{ml} \mathrm{CH} 3 \mathrm{COOH}$ for 2-3 seconds. The microstructure of the samples was studied using an OLYMPUS GX51 inverted metallographic microscope equipped with an OLYMPUS DP12 digital camera. The phase composition was also observed and analyzed using a JEOL JSM-6490LV scanning electron microscope. 


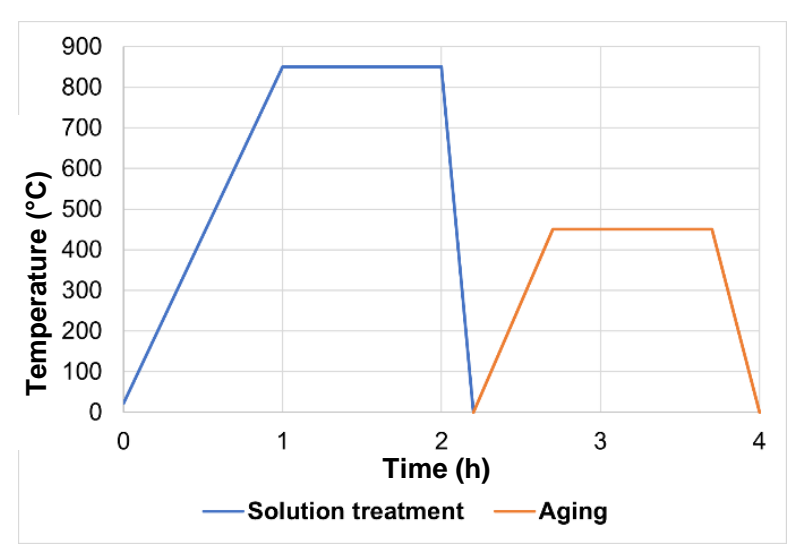

Figure 1 Schematic illustration of thermal treatment

The laboratory system Setaram SENSYS Evo TG/DSC equipped with highly sensitive 3D differential scanning calorimetry (DSC) sensors was used for determine the transformation temperatures of the samples and evaluate the heat treatment effect on the transformation temperatures. The DSC analysis was performed on the samples in as-received and heat treated stages placed in a corundum crucible under He gas (purity of $6 \mathrm{~N}$ ). From the temperature of $20^{\circ} \mathrm{C}$, the sample was cooled at a rate of $5{ }^{\circ} \mathrm{C} / \mathrm{min}$ to $-105^{\circ} \mathrm{C}$, and then tempered at this temperature for $5 \mathrm{~min}$. Subsequently, the sample was heated at a rate of $5{ }^{\circ} \mathrm{C} / \mathrm{min}$ from $-105^{\circ} \mathrm{C}$ up to a temperature of $60^{\circ} \mathrm{C}$, and then tempered at this temperature for 5 minutes.

The effect of the solution treatment and aging on the change in microhardness was investigated using an automatic microhardness tester FUTURE-TECH FM-100 with a control unit FM-ARS900. The measurement of $\mathrm{HV}$ values was performed with load of $100 \mathrm{~g}$ for $10 \mathrm{~s}$.

\section{RESULTS AND DISCUSSION}

\subsection{Chemical and microstructural analysis}

The chemical composition of NiTi sheet in as-received stage measured by spectroscopic analysis revealed an average content of $55.9 \mathrm{wt} \% \mathrm{Ni}$ and $0.03 \mathrm{wt} \% \mathrm{Fe}$. The SEM EDX analysis confirmed the content of $54.9 \mathrm{wt} \%$ $\mathrm{Ni}$ in the matrix and $57.1 \mathrm{wt} \% \mathrm{Ni}$ in very fine $\mathrm{Ni}_{4} \mathrm{Ti}_{3}$ particles of a lenticular shape. In the structure of the alloy the oxides based on Ti-Ni-O were detected. In heat treated conditions no other phases besides the matrix and oxides were analyzed.

The microstructure in the as-received stages presented in Figure 2 a). The transversal section of the sheet shows martensitic needles oriented in different directions, as well as clusters of these needles. There was also a band of needles observed in the etched structure, which propagated over the entire cross section of the sample. The occurrence of the needles band can be related with the NiTi sheet processing.

Figure $\mathbf{2} \mathbf{b}$ ) shows the microstructure of the transversal section of the sheet in the solution treated condition. Martensitic needles appeared in the structure and grains with the size up to $100 \mu \mathrm{m}$ were also revealed. Martensitic needles appear in the center of the sample, while grains and a small number of needles are visible at the edges. Furthermore, there are oxide particles observed in the structure, which are arranged into the lines.

Figure $2 \mathrm{c}$ ) shows the microstructure of the transversal section of the sheet after the solution and subsequent aging treatment. By etching the surface, the grain boundaries were well highlighted and the grain size reached of about 20-60 $\mu \mathrm{m}$. After aging, $\mathrm{Ni}_{4} \mathrm{Ti}_{3}$ phases of lenticular shape should appear, however the fine particles were not detected even by high magnification of SEM observation. However, longitudinal particles present in the microstructure analyzed by the SEM EDX analysis as oxide phases remained aligned. 

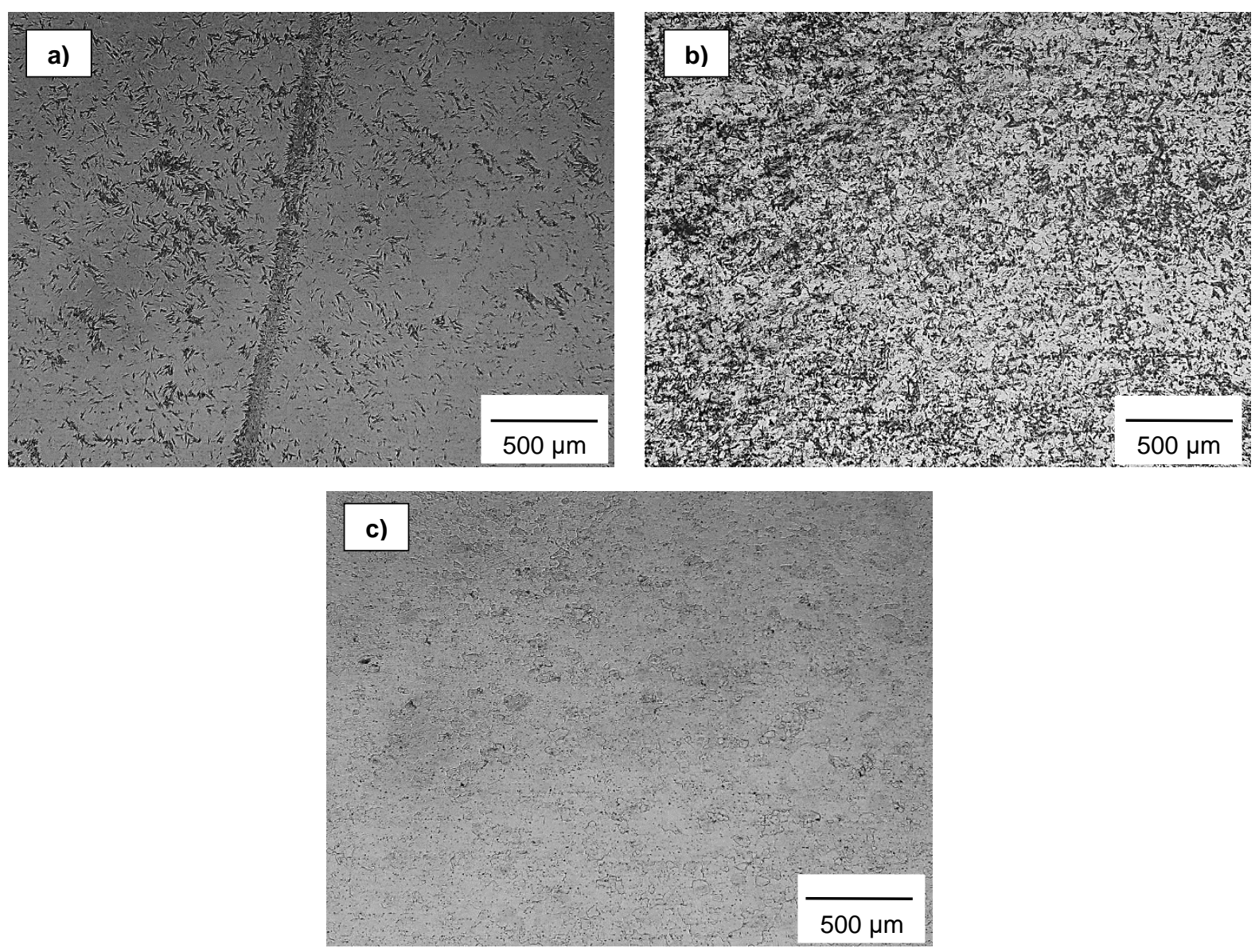

Figure 2 Microstructure of the sample in the a) as-received state, b) after solution treatment, $\mathbf{c}$ ) after solution treatment and aging

\subsection{Differential scanning calorimetry}

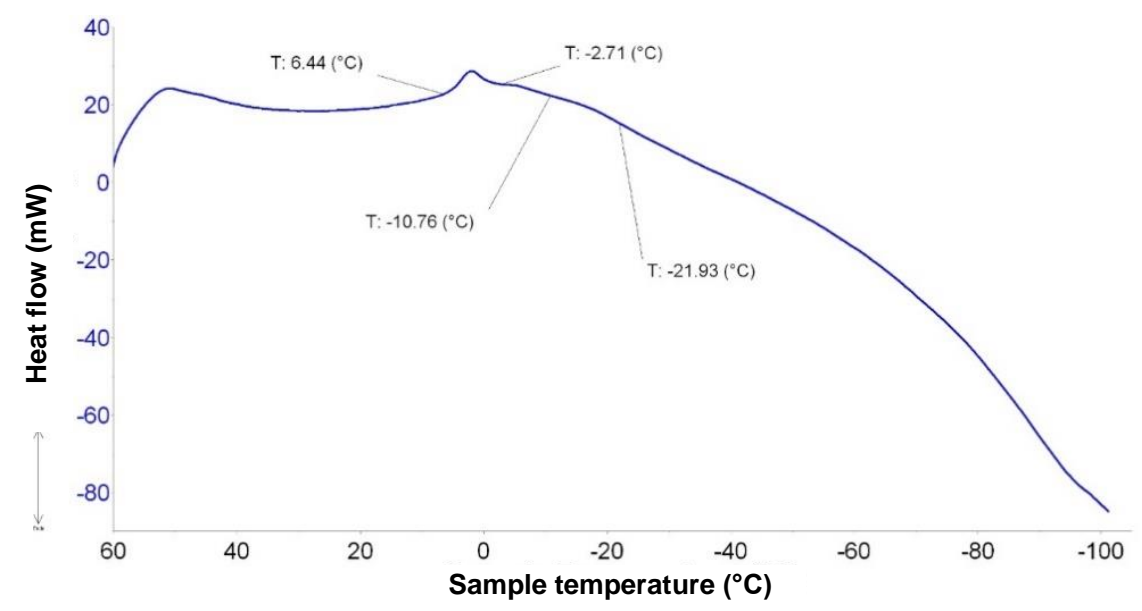

Figure $3 \mathrm{DSC}$ curve at $5{ }^{\circ} \mathrm{C} / \mathrm{min}$ of cooling rate or the as-received stage

Figure 3 shows the DSC curve of the sample in the as-received stage after the cooling. From the curve it is possible to identify the temperature interval when the $\mathrm{R}$ phase appeared and the temperature interval for the formation of martensite. It is obvious that $M_{s}$ temperature is shifted to higher value and the existence interval of martensite phase is enlarged for both heat treated samples, as seen in the next tables. Using analysis at 
heating, the transformation $A_{f}$ temperature was determined as $46{ }^{\circ} \mathrm{C}$ for the sheet in the as-received stage (Table 2) unlike $A_{f}$ temperature of $15{ }^{\circ} \mathrm{C}$ guaranteed by the supplier. Transformation temperatures measured after the thermal treatment were subsequently affected. After the solid solution treatment, the $A_{f}$ temperature of the sheet dropped to $38^{\circ} \mathrm{C}$ (Table 3). Conversely, aging increased the $A_{f}$ temperature to the value of $47^{\circ} \mathrm{C}$ (Table 4). The existence of $R$ phase was detected only for the as-received stage (analysis at cooling) and the solution treated and aged condition (analysis at cooling and heating). The $R_{s}$ and $R_{f}$ temperatures are influenced by heat treatment similarly as for $M_{s}$ and $M_{f}$. The changes in the values and intervals of transformation temperatures reflect processing technologies as well as heat treatment processes.

Table 2 Transformation temperatures $\left({ }^{\circ} \mathrm{C}\right)$ of the sample in the as-received stage

\begin{tabular}{|c|c|c|c|c|c|c|}
\hline & $\boldsymbol{M}_{\boldsymbol{s}}$ & $\boldsymbol{M}_{\boldsymbol{f}}$ & $\boldsymbol{R}_{\boldsymbol{s}}$ & $\boldsymbol{R}_{\boldsymbol{f}}$ & $\boldsymbol{A}_{\boldsymbol{s}}$ & $\boldsymbol{A}_{\boldsymbol{f}}$ \\
\hline Cooling & -11 & -22 & 6 & -3 & - & - \\
\hline Heating & - & - & - & - & 8 & 46 \\
\hline
\end{tabular}

Table 3 Transformation temperatures $\left(\right.$ in ${ }^{\circ} \mathrm{C}$ ) of the sample after the solution treatment

\begin{tabular}{|c|c|c|c|c|c|c|}
\hline & $\boldsymbol{M}_{\boldsymbol{s}}$ & $\boldsymbol{M}_{\boldsymbol{f}}$ & $\boldsymbol{R}_{\boldsymbol{s}}$ & $\boldsymbol{R}_{\boldsymbol{f}}$ & $\boldsymbol{A}_{\boldsymbol{s}}$ & $\boldsymbol{A}_{\boldsymbol{f}}$ \\
\hline Cooling & -3 & -27 & - & - & - & - \\
\hline Heating & - & - & - & - & 6 & 38 \\
\hline
\end{tabular}

Table 4 Transformation temperatures (in ${ }^{\circ} \mathrm{C}$ ) of the sample after the solution and aging treatment

\begin{tabular}{|c|c|c|c|c|c|c|}
\hline & $\boldsymbol{M}_{\boldsymbol{s}}$ & $\boldsymbol{M}_{\boldsymbol{f}}$ & $\boldsymbol{R}_{\boldsymbol{s}}$ & $\boldsymbol{R}_{\boldsymbol{f}}$ & $\boldsymbol{A}_{\boldsymbol{s}}$ & $\boldsymbol{A}_{\boldsymbol{f}}$ \\
\hline Cooling & -6 & -32 & 35 & 20 & - & - \\
\hline Heating & - & - & 9 & 28 & 40 & 47 \\
\hline
\end{tabular}

\subsection{Microhardness measurement}

The highest microhardness HVO.1 values were measured for the samples in the as-received stage. In contrast, the samples after solution treatment reached the lowest microhardness, as seen in Table 5. The high values for the as-received samples are related probably with forming during sheet metal processing. The decrease in microhardness after annealing is due to the phase transformation from martensitic to austenitic phase. Furthermore, the decrease is also related to the elimination of internal stress caused by the sheet processing. Slightly increasing in the average microhardness value for the aged sample can be related to $\mathrm{R}$ phase.

Table 5 Average Vickers microhardness values HVO.1 for the samples in different heat treatment conditions

\begin{tabular}{|c|c|}
\hline Sample & HVO.1 \\
\hline As received - transversal section & $273 \pm 16$ \\
\hline As received - upper surface & $269 \pm 12$ \\
\hline Solution treated - transversal section & $245 \pm 16$ \\
\hline Solution treated + aged - transversal section & $248 \pm 17$ \\
\hline
\end{tabular}

\section{CONCLUSION}

The metallographic analysis of the flat samples obtained of the sheet revealed the presence of martensitic needles and oxide particles in the microstructure for various heat treatment conditions. In some cases, the bands associated with the accumulation of deformation energy during sheet processing were also observed. 
The results of the DSC analysis showed differences of the transformation temperatures indicated by the supplier. However, the heat treatment shifted the transformation temperatures. After the solution annealing, $A_{f}$ temperature was the lowest. On the contrary, the subsequent aging led to the highest $A_{f}$ temperature. The changes in the values and intervals of all transformation temperatures were affected by processing technologies as well as heat treatment processes.

The highest values of the HVO.1 microhardness corresponded to the as-received stage of the sheet. The heat treatment led into the decrease of the microhardness values.

\section{ACKNOWLEDGEMENTS}

This work has been realized in the framework of the following projects: FV40306 "Development of new implants for the regulation of lower limb growth in a sterile design", as well as within the projects SGS SP2021/41 "Specific research in metallurgical, material and processing engineering" and SP2021/62 "Materials based on non-ferrous metals - preparation, procedures for improving their properties, areas of application and the possibility of recycling selected types of waste".

\section{REFERENCES}

[1] OTSUKA, K., REN, X. Recent developments in the research of shape memory alloys. Intermetallics. [online]. 1999, vol. 7, no. 5, pp. 511-528. Available from: https://doi.org/10.1016/S0966-9795(98)00070-3.

[2] REN, D.C., ZHANG, H.B., LIU, Y.J., LI, S.J., JIN, W., YANG, R., ZHANG, L.C. Microstructure and properties of equiatomic Ti-Ni alloy fabricated by selective laser melting. Materials Science and Engineering: A. [online]. 2020, vol. 771. Available from: https://doi.org/10.1016/i.msea.2019.138586.

[3] WANG, Z., EVERAERTS, J., SALVATI, E., KORSUNSKY, A.. Evolution of thermal and mechanical properties of Nitinol wire as a function of ageing treatment conditions. Journal of Alloys and Compounds. [online]. 2020, p. 819. Available from: https://doi.org/10.1016/i.jallcom.2019.153024.

[4] OTSUKA, K., REN, X. Physical metallurgy of Ti-Ni-based shape memory alloys. Progress in Materials Science. [online]. 2005, vol. 50, no. 5, pp. 511-678. Available from: https://doi.org/10.1016/.pmatsci.2004.10.001.

[5] MOHD JANI, J., LEARY, M., SUBIC, A., GIBSON, M. A review of shape memory alloy research, applications and opportunities. Materials \& Design. [online]. 2014, vol. 56, pp.1078-1113. Available from:

https://doi.org/10.1016/i.matdes.2013.11.084.

[6] SAFDEL, A., ZAREI-HANZAKI, A., SHAMSOLHODAEI, A., KROOß, P., NIENDORF, T. Room temperature superelastic responses of $\mathrm{NiTi}$ alloy treated by two distinct thermomechanical processing schemes. Materials Science and Engineering: A. [online]. 2017, vol. 684, pp. 303-311. Available from:

https://doi.org/10.1016/..msea.2016.12.047.

[7] PATOOR, E., LAGOUDAS, D., ENTCHEV, P., BRINSON, L., GAO, X. Shape memory alloys, Part I: General properties and modeling of single crystals. Mechanics of Materials. [online]. 2006, vol. 38, no. 5-6, pp. 391-429. Available from: https://doi.org/10.1016/j.mechmat.2005.05.027. 